\section{Uma visão multirrepresentacional dos padrões silábicos emergentes do português brasileiro}

\section{A multi-representational view of emerging syllabic patterns in Brazilian Portuguese}

Anderson Romário SOUZA (UERN) souzaandersonr@hotmail.com

Antônia Rayane BARRA (UERN) rayanebarra@outlook.com

Clerton Luiz Felix BARBOZA (UERN) clertonluiz@gmail.com

Recebido em: 25 de out. de 2019. Aceito em: 13 de jan. de 2020.
SOUZA, Anderson Romário;

BARRA, Antônia Rayane; BARBOZA Clerton Luiz Felix. Uma visão multirrepresentacional dos padrões silábicos emergentes do português brasileiro. Entrepalavras, Fortaleza, v. 10 , n. 1 , p. $121-140$, jan-abr/2020 DOI: $10.22168 / 2237-6321-11735$.
Resumo: O objetivo deste estudo é analisar Padrões Silábicos Emergentes (PSE) em contexto heterossilábico no Português Brasileiro (PB). Temos por perguntaproblema: quais os fatores associados à emergência de PSE heterossilábicos no PB? Como hipótese básica, acredita-se que os PSE no PB emergem pela redução gradiente da vogal epentética, culminando em sua não realização categórica, influenciada por variáveis como tipo silábico, vozeamento e indivíduo. Esta pesquisa baseia-se na visão de língua(gem) enquanto Sistema Adaptativo Complexo (SAC) (BECKNER et al, 2009) e nos modelos fonológicos multirrepresentacionais (BYBEE, 2001). Este estudo caracteriza-se como quaseexperimental e quantitativo, com os dados passando por análise acústica e estatística. Entre os principais resultados, constatouse que (1) os tipos silábicos influenciam de maneira distinta a emergência de PSE, (2) encontros consonantais desvozeados funcionam enquanto atratores de PSE, (3) a duração da vogal epentética não está relacionada à sua menor ou maior emergência categórica, (4) a vogal epentética apresenta menor duração que a vogal plena, além da (5) preferência pela realização de PSE $(71 \%)$ entre os informantes.

Palavras-chave: Sistema adaptativo complexo. Modelos multirrepresentacionais. Padrões silábicos emergentes. 
V. 10 (1)

121-140

jan./abr

2020

Abstract: This study aims to analyze Emerging Syllable Patterns (ESP) in heterosyllabic contexts in Brazilian Portuguese (BP). Our research question is: what are the factors associated with the emergence of heterosyllabic ESP in BP? As a hypothesis, we believe that ESP in BP emerge from the epenthetic vowel gradient elision culminating in its categorical non-realization, which is influenced by variables such as syllabic type, voicing, and individual. This research is based on a view of language as a Complex Adaptive System (CAS) (BECKNER et al, 2009) and the multi-representational phonologic models (BYBEE, 2001). This is a quasi-experimental and quantitative research, with the data undergoing acoustic and statistical analyses. Among the main results, it was observed that (1) syllabic types influence distinctively ESP emergence, (2) voiceless clusters work as ESP attractors, (3), the epenthetic vowel's length is not associated with its higher or lower rates of categorical emergence, (4) the epenthetic vowel has shorter length compared to the full vowel, as well as (5) the preference for ESP realization (71\%) among the informants.

Keywords: Complex Adaptive System. Multi-representational models. Emerging syllabic patterns.

\section{Introdução}

O objetivo desta pesquisa é analisar os Padrões Silábicos Emergentes (PSE) em contexto heterossilábico no Português Brasileiro (PB). A pergunta problema que norteia este estudo é: quais os fatores associados à emergência de PSE heterossilábicos no PB? A hipótese desta pesquisa é que os PSE no PB emergem pela redução gradiente da vogal epentética, influenciada por variáveis como tipo silábico, vozeamento e indivíduo. Esta pesquisa baseia-se na visão de língua(gem) enquanto Sistema Adaptativo Complexo (SAC) (LARSEN-FREEMAN, 2008; BECKNER et al, 2009) e nos preceitos dos Modelos Fonológicos Multirrepresentacionais (PIERREHUMBERT, 2001; BYBEE, 2001).

Pesquisas recentes observam a emergência de PSE no PB de maneira direta (CANTONI, 2015; NASCIMENTO, 2016) ou indiretamente através de pesquisas sobre a epêntese (EPE) vocálica (SILVEIRA; SEARA, 2009; PEIXOTO, 2011). Além disso, também foi analisada a gradiência da vogal (epentética e/ou plena) na emergência de PSE (CRISTÓFAROSILVA; ALMEIDA, 2008; NASCIMENTO, 2016). O presente estudo busca aprofundar a discussão ao analisar a EPE, além de padrões inovadores na língua, através de uma pesquisa quantitativa quase-experimental que contou com análises acústicas e estatísticas.

Com a execução desta pesquisa, objetiva-se contribuir para a compreensão da emergência de padrões silábicos no PB, já averiguada indiretamente na variante potiguar por Cristófaro-Silva et al (2012), Barboza (2013) e diretamente por Nascimento (2016). Embora o estudo da epêntese vocálica apresente ampla literatura, a consideração dos PSE 
a partir de sua não realização mostra-se um fenômeno mais pertinente no percurso de desenvolvimento do PB do que a simples averiguação tradicional da ocorrência ou não de epêntese.

Após esta breve seção de Introdução, é apresentada a Fundamentação teórica do trabalho. Após a revisão teórica, a seção Metodologia apresenta as informações metodológicas da pesquisa, seguida pelas Análises e resultados. Por fim, são apresentadas as Considerações finais do estudo.

\section{Fundamentação teórica}

Adotamos neste trabalho a visão de língua(gem) enquanto SAC (LARSEN-FREEMAN; CAMERON, 2008; BECKNER et al, 2009), dos Modelos Multirrepresentacionais compostos pela Fonologia de Uso (FU) (BYBEE, 2001) e da noção probabilística do Modelo de Exemplares (ME) (PIERREHUMBERT, 2001). Apresentamos a seguir uma breve discussão envolvendo a emergência de PSE no PB sob a ótica desses pressupostos.

A linguagem conta com atratores, os quais são determinados contextos que tendem a influenciar alguma característica do sistema. Como exemplo, consoantes vozeadas em posição de coda tendem a favorecer a inserção de EPE, como em ad(i)vogado. De modo distinto, consoantes desvozeadas em coda podem favorecer a emergência de PSE no PB, como em af( $\varnothing)$ ta. Porém, o próprio tipo silábico pode atuar como um atrator para a emergência de ambos os fenômenos, exemplificado por Nascimento (2016) ao relatar que ób( $\varnothing$ )vio, embora composta por um segmento vozeado, favorece PSE em vez da EPE. O conceito de atratores é fundamental para o estudo dos padrões silábicos, pois diversos fatores mostram-se em competição, apresentando maior ou menor influência para a realização de um PSE e consequente alteração do comportamento canônico do sistema.

A variação na duração da vogal pode indicar um percurso de desenvolvimento dinâmico, cuja característica principalé sofrer mudanças ao longo do tempo. À medida que a duração da vogal diminui e ocorre o fenômeno de elisão da vogal epentética, constitui-se a emergência de um PSE. Além disso, a linguagem também se caracteriza como um sistema aberto, pois conta com a influência de sistemas externos. O sistema alfabético do PB influencia na pronúncia das palavras dessa língua, a qual tende a ter marcante correspondência grafofônica ao aprendermos línguas adicionais. 
V. 10 (1) 121-140 jan./abr 2020

Por sua vez, a utilização dos Modelos Multirrepresentacionais assume que as representações linguísticas são múltiplas e detalhadas (BYBEE, 2001; PIERREHUMBERT, 2001). Inexiste neste caso a separação entre fatos fonéticos e fatos fonológicos, peculiar às teorias fonológicas tradicionais. Para esse modelo, as representações fonológicas correspondem diretamente àquelas encontradas na realização fonética ${ }^{1}$.

Para esta visão, a palavra é o lócus da representação mental. O armazenamento linguístico é realizado através de nuvens de exemplares. Itens lexicais, adquiridos pelo uso da língua, são armazenados de acordo com aspectos sonoros, semânticos ou morfológicos. O detalhe fonético é considerado nas representações fonológicas. A realização dos exemplares é baseada em escolhas probabilísticas, com itens de maior frequência apresentando maior robustez em seus exemplares (BYBEE, 2001; PIERREHUMBERT, 2001).

Assim, tais teorias consideram que o sistema fonético/ fonológico é múltiplo e detalhado, que há uma inter-relação entre os diversos sistemas linguísticos, com a variação presente no percurso individual de construção linguística dos falantes. Passamos à abordagem do fenômeno analisado, além de estudos sobre o tema no PB.

A Figura 1 apresenta a palavra afta sob uma visão tradicional de representação silábica, a qual conta com o tipo silábico f.t. Embora este estudo vá de encontro à visão autossegmental, a representação arbórea exemplifica as posições de onset e coda ocupadas pelos segmentos. Na primeira realização emerge uma vogal epentética, enquanto na segunda ocorre um PSE.

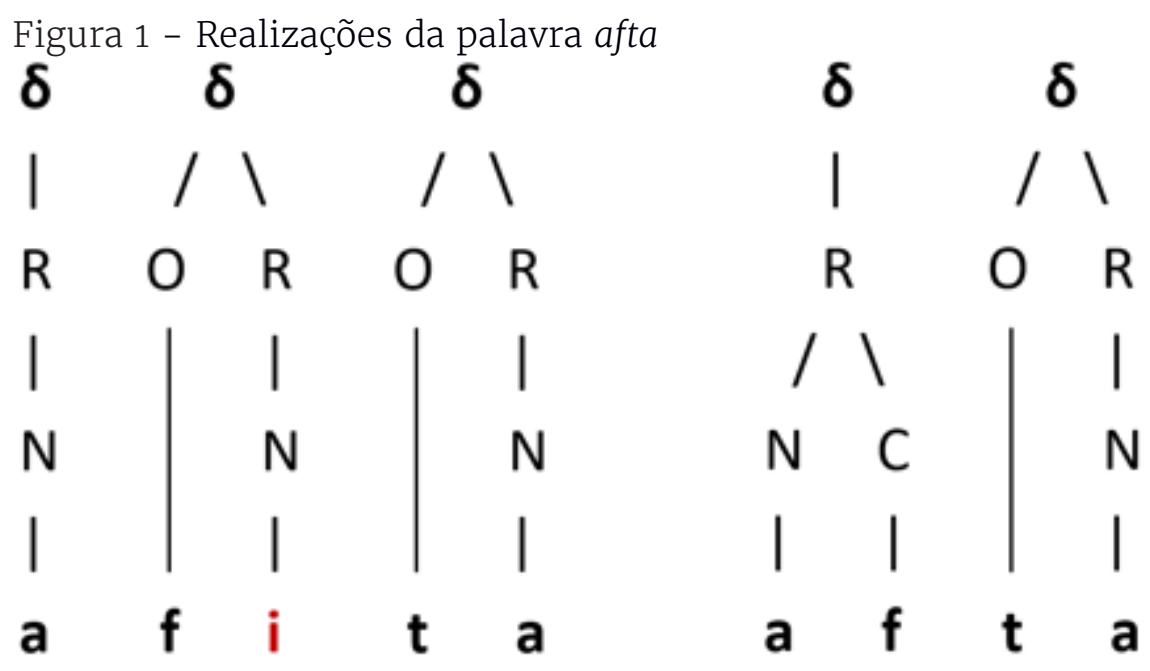

Fonte: Elaboração própria.

${ }^{1}$ Por este motivo, esta pesquisa apresenta transcrições do sistema fonético/fonológico em negrito em vez de $/ . . . /$ e $[\ldots]$. 
Na primeira realização, nota-se a emergência da vogal epentética $\mathbf{i}$. A consoante $\mathbf{f}$ torna-se o onset de uma sílaba emergente composta pela vogal epentética como núcleo. Na segunda realização, encontram-se a fricativa $\mathbf{f}$ em posição de coda da primeira sílaba e a oclusiva $\mathbf{t}$ em onset da sílaba seguinte. Tal realização caracteriza-se como um PSE, pois conta com um encontro consonantal heterossilábico inesperado no $\mathrm{PB}$.

Assim, retomando a fundamentação deste estudo, acreditase que, à medida que a vogal epentética tem sua duração reduzida e finalmente deixa de ser realizada, o PB passa a favorecer a emergência de PSE. A redução gradiente da epêntese pode ser influenciada por atratores linguísticos, propiciando a emergência de PSE. O comportamento individual dos falantes também pode favorecer a ocorrência de PSE, bem como é esperada variação no nível lexical. Além disso, acredita-se que há competição entre representações com um PSE e com a EPE, das quais os exemplares com maior frequência de uso tendem à maior emergência de modo probabilístico. Estudos que reforçam essa perspectiva são discutidos a seguir.

Silveira e Seara (2009) analisaram as características acústicas da EPE vocálica em contextos consonantais heterossilábicos no PB. A taxa de emergência geral de EPE foi de 73\% e a média da duração relativa constatada foi de 2,92. Os dados mostram que, de acordo com o contexto consonantal, a EPE obteve as seguintes médias: nasais $(3,19)$ fricativas (3) e plosivas $(4,78)$. Vogais epentéticas de palavras em frases veículos $(4,92)$ foram mais longas do que em palavras isoladas $(3,46)$. Por fim, a EPE em posição pretônica $(4,26)$ obteve uma média de duração relativa menor que a postônica $(4,05)$.

Cristófaro-Silva e Almeida (2008) analisaram a realização de EPE e a elisão da vogal plena em contextos semelhantes, como nas palavras apitar e optar. Percebeu-se diferença significativa entre os índices de EPE em consoantes vozeadas (88\%) e desvozeadas (74\%). Adicionalmente, foi apontado que a duração da EPE vocálica (30 ms) é significativamente menor do que a duração da vogal plena (49 ms). Segundo os autores, como as representações fonológicas são múltiplas e detalhadas no modelo multirrepresentacional, os informantes contam com exemplares com vogais plenas (a.pi.'tah), com EPE (o.pi.'tah) e sem vogal alguma (ap.' tah / op.' tah).

Peixoto (2011) analisou a duração das vogais plenas e vogais epentéticas nos pares mínimos pais/paz, reis/rês e pois/pôs. A duração 
V. 10 (1) $121-140$ jan./abr 2020

relativa das vogais epentéticas nas três palavras foi menor do que a vogal plena, embora tenha sido significativa apenas nos pares pais/paz e pois/pôs. Tal resultado alinha-se aos achados de Cristófaro-Silva e Almeida (2008), dando suporte à noção de gradiência do fenômeno.

Cantoni (2015) estudou a vogal epentética tônica em itens lexicais específicos numa visão multirrepresentacional. Foram selecionadas palavras cujas vogais epentéticas poderiam reestruturar o acento silábico, como em ritmo (hi. 't tji.mu). Observou-se que vogais epentéticas tônicas (o.'pi.tv) emergiram em número significativamente maior do que vogais epentéticas átonas ('o.pi.tv). Quanto à duração relativa, a vogal plena tende à maior duração, seguida pela vogal epentética tônica e, por fim, pela vogal epentética átona. Além disso, reforçou-se a relevância da análise do item lexical ao constatar diferenças significativas em palavras diferentes.

Nascimento (2016) analisou a manifestação de PSE no PB e suas influências para a aquisição dos padrões silábicos do inglês. A pesquisa atestou que a emergência de PSE no PB não é influenciada pela aquisição do inglês. Além disso, a autora apontou indícios de correlação positiva entre o número de ocorrências de EPE e sua duração. Tipos silábicos que atuaram como atratores (k.t, p.t, f.t, d.v, d.k, b.d, b.v); contextos desvozeados (afta) favoreceram significativamente o PSE se comparados aos vozeados (advogado); e sílabas postônicas (afta) favoreceram mais os PSE do que as pretônicas (aftosa). Observou-se o percurso próprio dos itens lexicais, como em óbvio, a qual é formada pelo tipo silábico vozeado b.v, mas obteve índices de PSE maiores que 90\%. Finalmente, percebeu-se diferença apenas não significativa entre a duração relativa das vogais plenas e epentéticas.

Os resultados apresentados nesta seção vão ao encontro dos princípios dos modelos multirrepresentacionais, pois apontam uma gradiência influenciada por atratores linguísticos na realização da vogal epentética. Através dos estudos aqui apresentados, percebe-se que falantes distinguem a vogal epentética da vogal plena na realização através da duração reduzida (CRISTÓFARO-SILVA; ALMEIDA, 2008; PEIXOTO, 2011). Porém tal distinção não foi confirmada na pesquisa de Nascimento (2016). Entre as variáveis linguísticas que podem influenciar a duração da vogal epentética, destacam-se o tipo silábico, a utilização de frases veículos e a posição pretônica (SILVEIRA; SEARA, 2009). Também se atestou a influência do vozeamento (CRISTÓFAROSILVA; ALMEIDA, 2008). Por fim, se percebeu o percurso distinto dos 
itens lexicais em relação à duração das vogais epentéticas (CANTONI, 2015; NASCIMENTO, 2016), além da ordem decrescente na duração das vogais: vogal plena > vogal epentética tônica > vogal epentética átona (CANTONI, 2015). A próxima seção apresenta os procedimentos metodológicos desta pesquisa.

\section{Metodologia}

O estudo caracteriza-se como uma pesquisa quaseexperimental, quantitativa, de cunho transversal que contou com os dados do Estudo longitudinal do desenvolvimento do sistema sonoro do inglês por aprendizes brasileiros: uma perspectiva dinâmica². Foram selecionados 20 informantes de semestres iniciais do curso de Letras - Inglês da UERN. A coleta de dados ocorreu entre os semestres 2017.1 e 2018.2.

A coleta dos dados foi realizada na própria universidade, em sala silenciosa sem tratamento acústico. Voluntariaram-se informantes de ambos os sexos, com idade de 17 a 35 anos, naturais de diversas cidades do Rio Grande do Norte e relataram jamais terem viajado ao exterior ou estudarem línguas adicionais além do inglês. As informações pertinentes à delimitação das variáveis são apresentadas a seguir.

Duas variáveis dependentes foram objeto deste estudo. A realização de PSE caracteriza-se como uma variável categórica, a qual busca analisar se há ou não emergência de PSE nas palavras selecionadas. Já a duração relativa da vogal busca analisar a duração das vogais epentética e plena, caracterizando assim uma variável gradiente. A seguir apresentamos as variáveis independentes desta pesquisa: (a) Tipo silábico: segundo a literatura, alguns tipos silábicos funcionam como atratores para a realização de PSE. Foram selecionados os tipos silábicos heterossilábicos k.t, f.t, p.t, d.v, d.m e b.v; (b) Vozeamento: hipotetizamos que tipos silábicos desvozeados favorecem a emergência de PSE. Adicionalmente, temos por hipótese que os tipos desvozeados apresentarão EPE com menor duração; (c) Indivíduo: observamos o comportamento individual dos informantes. Acredita-se que cada indivíduo apresenta características distintas quanto à emergência de PSE.

Seis palavras foram selecionadas para analisar a emergência de PSE no PB. Duas palavras foram utilizadas para averiguar a duração da vogal plena. As oito palavras são expostas no Quadro 1.

${ }^{2} \mathrm{O}$ objetivo do projeto é investigar a trajetória do desenvolvimento do sistema sonoro do inglês como L2. Uma parceria entre a UERN, UFRGS, UFC e UFSC. 
V. 10 (1)

121-140

jan./abr.

2020
Quadro 1 - Palavras selecionadas

\begin{tabular}{|c|c|c|c|c|c|}
\cline { 2 - 5 } \multicolumn{1}{c|}{} & \multicolumn{3}{c|}{ EPÊNTESE } & \multicolumn{2}{|c|}{ VOGAL PLENA } \\
\hline k.t & pacto & d.v & advogado & & tico \\
f.t & afta & d.m & administrar & \multirow{2}{*}{ i } & quico \\
\cline { 1 - 3 } p.t & apto & b.v & óbvio & & \\
\hline
\end{tabular}

Fonte: Elaboração própria.

Para cada tipo silábico, apenas uma palavra foi selecionada. Para a comparação das durações relativas da vogal plena e epentética, foram selecionadas duas palavras com a vogal i plena.

O experimento desta pesquisa consistiu na leitura de dois tipos de frases-veículo: a) em temos " $X$ "; e, b) têm X sílaba(s). As frases foram apresentadas aos informantes em slides. Cada sentença foi repetida três vezes. No total, analisamos 24 ocorrências (sendo 18 propícias a PSE) por indivíduo e 480 realizações ao todo.

Foi realizada uma análise acústica com o auxílio do software PRAAT versão 6.0.32 (BOERSMA; WEENIK, 2019). O objetivo desta análise foi constatar a emergência de PSE ou de EPE, além de medir a duração relativa das vogais plena e epentética.

A Figura 2 apresenta a realização da palavra afta pelo informante 6. Nota-se que, entre a fricativa $\mathbf{f}$ e a oclusiva $\mathbf{t}$, não há presença de ondas sonoras periódicas no oscilograma ou formantes no espectrograma. Conclui-se que houve a emergência do PSE VC.CV com f.t.

Figura 2 - Oscilograma e espectrograma da palavra afta com PSE

\section{I6afta}

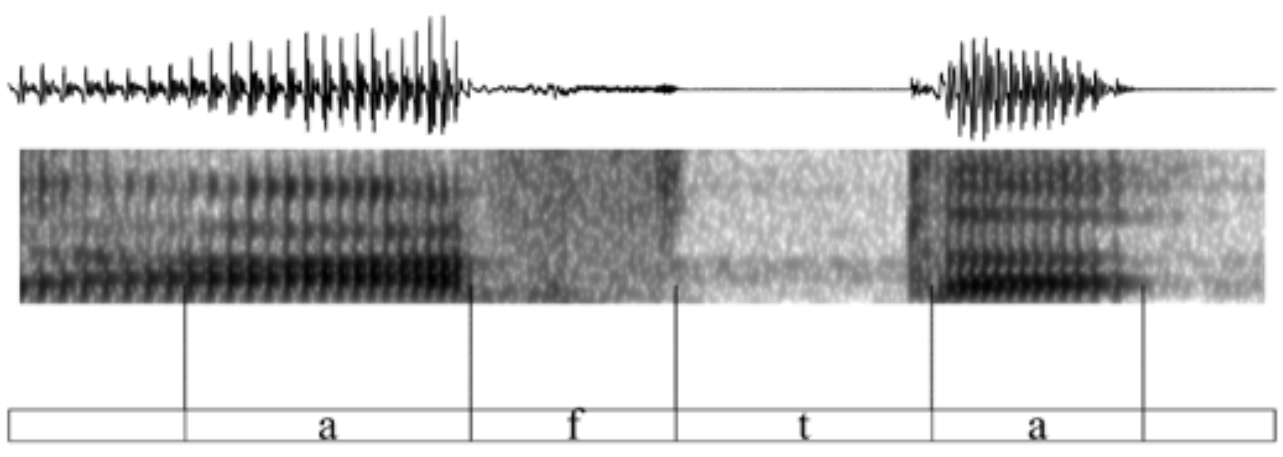

0,433

Fonte: Elaboração própria.

Por sua vez, a Figura 3 apresenta uma segunda realização da mesma palavra pelo informante 6 , dessa vez com uma vogal epentética. 
Figura 3 - Oscilograma e espectrograma da palavra afta com EPE

\section{I6afta2}

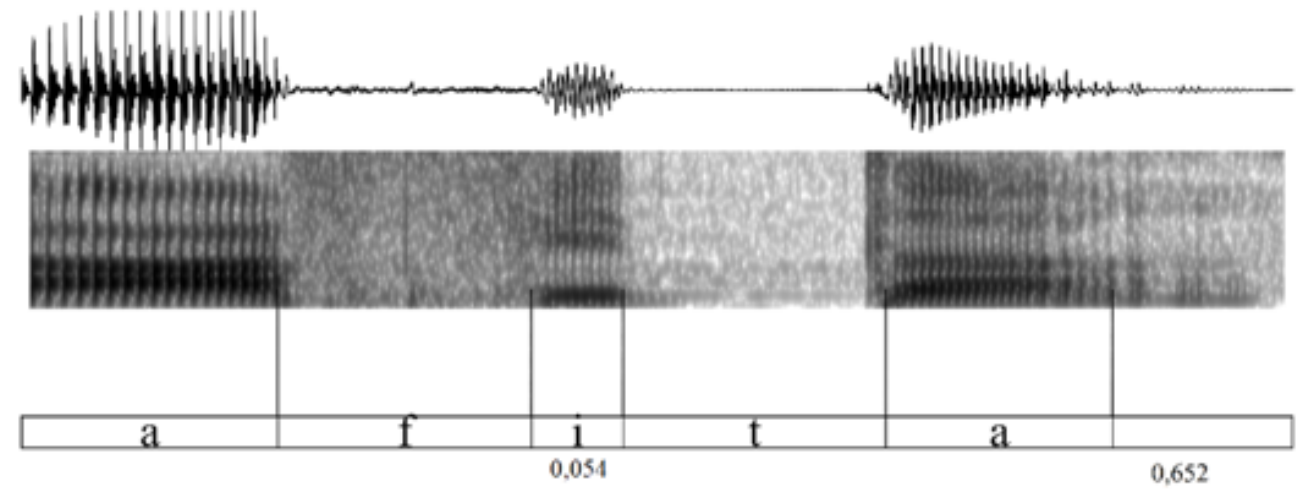

Fonte: Elaboração própria.

Aárea destacada pelo segmento i corresponde à vogal epentética emergente entre as consoantes $\mathbf{f}$ e $\mathbf{t}$. Assim, torna-se possível analisar a duração da vogal (54 ms). Ao dividir a duração da vogal pela duração da palavra (652 ms), obtém-se a duração relativa para esta vogal $(0,08)$, representada nessa pesquisa em números decimais.

Para a análise estatística, foi utilizado o software SPSS Statistics versão 20.0 (IBM CORPORATION, 2011). Os testes estatísticos utilizados foram o qui-quadrado para as análises categóricas. Para as análises gradientes, testes paramétricos e não paramétricos foram utilizados de acordo com recomendações da literatura (DANCEY; REIDY, 2006). Na próxima seção apresentamos a análise e discussão dos dados desta pesquisa.

\section{Análises e resultados}

Iniciamos a discussão analisando a variável tipo silábico buscando averiguar o comportamento dos tipos analisados em relação à emergência de PSE. A Figura 4 apresenta os resultados da análise categórica para o tipo silábico, a qual apresenta as ocorrências de PSE e EPE. 
V. 10 (1) 121-140 jan./abr. 2020

Figura 4 - Realização de PSE por tipo silábico

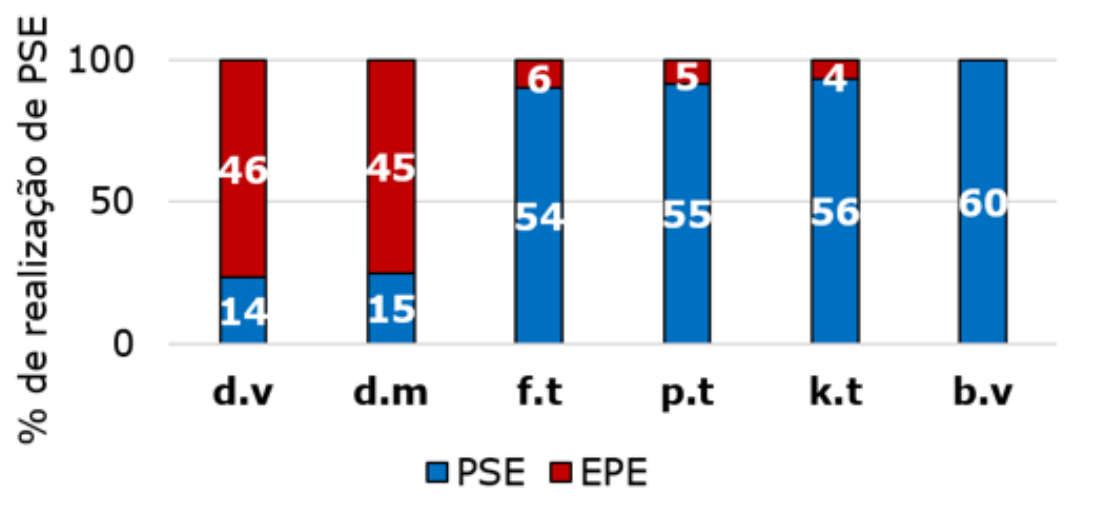

Fonte: Elaboração própria.

Dados referentes ao tipo silábico b.v não foram utilizados na análise estatística, devido à emergência categórica de PSE. O tipo silábico b.v, nesta pesquisa, provou-se altamente resistente à inserção de vogal epentética, favorecendo o PSE em óbvio. Nascimento (2016) também constatou altos índices de PSE para este item lexical.

Ao constatarmos a diferença significativa $\left(\mathrm{x}^{2}(4)=143,7\right.$; $\mathrm{p}<$ 0,01) entre os tipos silábicos restantes, percebe-se que k.t, f.t, p.t e b.v atuam como atratores para a emergência de PSE no PB. Porém, os tipos d.v e d.m favoreceram a emergência de EPE. A Figura 5 apresenta dados de duração relativa da vogal nos casos de EPE quanto aos distintos tipos silábicos na forma de Boxplots e intervalos de confiança de 95\%.

Figura 5 - Duração relativa da vogal epentética por tipo silábico
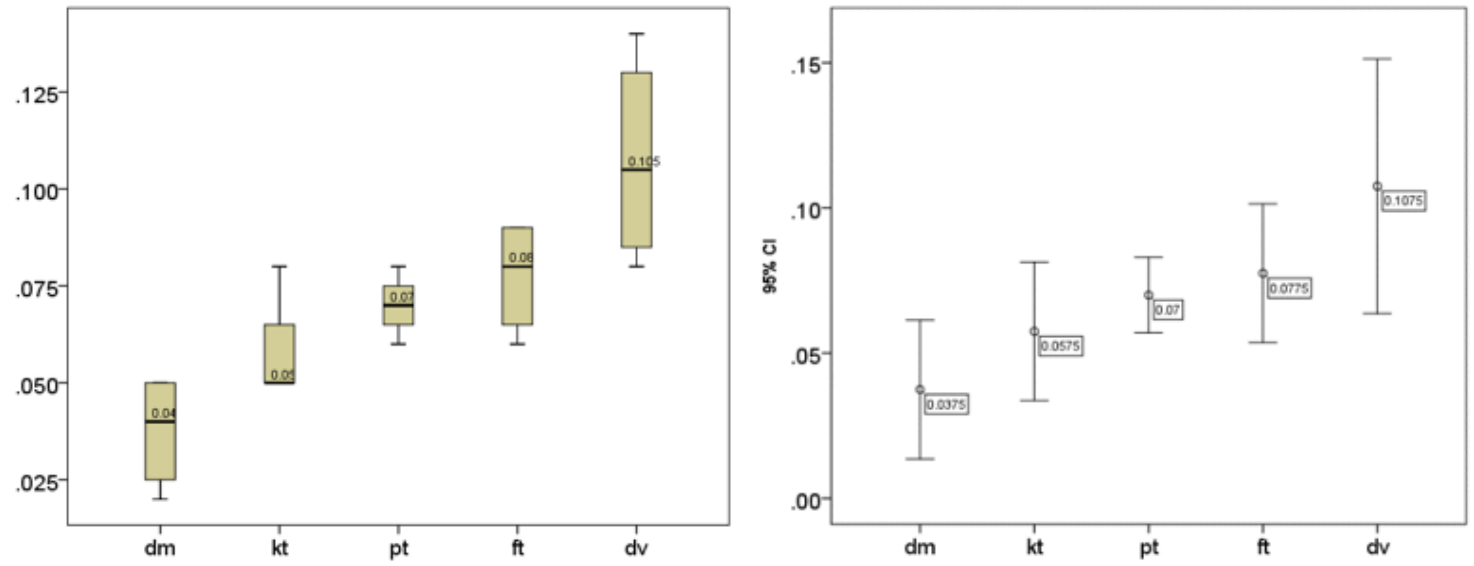

Fonte: Elaboração própria.

Foi utilizado o Teste estatístico de Friedman e o resultado $\left(\mathrm{X}^{2}(4)=11,63 ; p=0,02\right)$ mostrou que os tipos silábicos apresentaram vogais epentéticas com durações relativas significativamente distintas do ponto de vista estatístico. 
Mais uma vez, o tipo b.v não foi considerado, pois não contou com ocorrências de EPE. O tipo silábico com maior duração relativa da EPE foi d.v com 0,08, além de apresentar o maior número de ocorrências de EPE (46). Entretanto, o tipo d.m que apresentou 45 ocorrências de EPE, contou com a menor duração relativa da vogal $(0,05)$. O resultado é distinto do reportado por Nascimento (2016). A pesquisadora constatou, naquele momento, que quanto maior o número de ocorrências de EPE, maior a duração da vogal por tipo silábico. Entretanto, deve-se mencionar que pesquisa atual contou com apenas uma palavra por tipo silábico, não sendo possível averiguar se tais resultados aplicam-se a outros itens lexicais.

Os tipos silábicos k.t, f.t e p.t apresentaram poucas ocorrências deEPE e obtiveram duração relativa de 0,05, 0,06 e 0,06, respectivamente. Novamente, percebe-se que a quantidade de ocorrências de EPE não está relacionada à maior duração da vogal. Os tipos silábicos f.t e p.t apresentaram respectivamente apenas seis e cinco emergências de EPE, porém obtiveram duração relativa média de 0,06, maior do que o tipo d.m que contou com 45 ocorrências de EPE e duração relativa média de 0,05 .

Como resultado geral e baseando-se nos SACs, os tipos silábicos f.t, p.t, k.t e b.v atuaram como atratores para os PSE enquanto d.m e d.v foram atratores da vogal epentética. Em relação à duração da vogal epentética, notou-se que a duração da vogal não está associada ao número de ocorrências de EPE na palavra, mas sim a comportamentos distintos de cada tipo silábico. A seguir são apresentados os resultados para a variável vozeamento.

O objetivo desta variável foi observar como o vozeamento das consoantes dos tipos silábicos influencia a emergência de PSE no PB, além da influência na duração da EPE. A Figura 6 apresenta os dados categóricos dessa variável, relatando o total de ocorrências de PSE e EPE em cada contexto. 
V. 10 (1) 121-140 jan./abr. 2020
Figura 6 - Realização de PSE por vozeamento

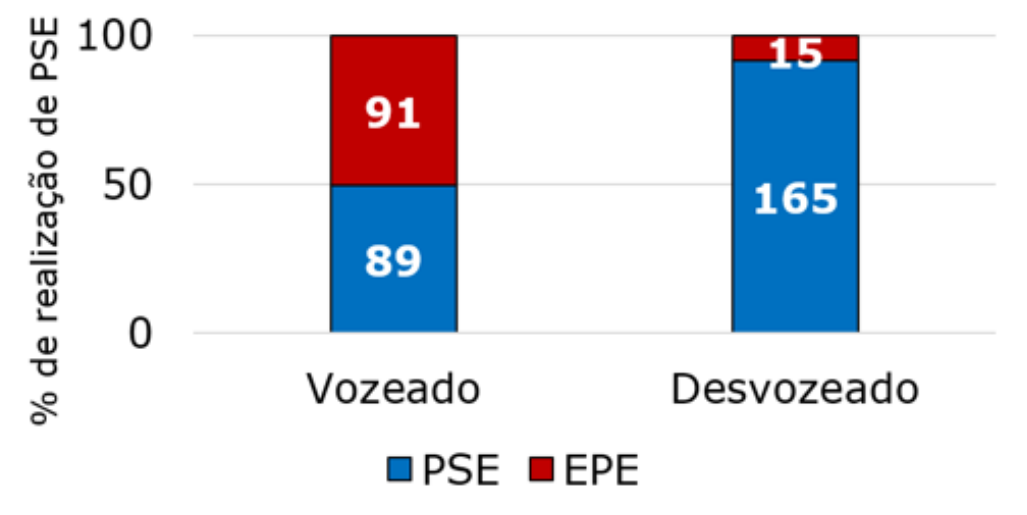

Fonte: Elaboração própria.

Os tipos silábicos desvozeados (f.t, k.t, p.t) contaram com apenas 15 ocorrências de EPE e 165 emergências de PSE. Já os tipos silábicos vozeados (d.v, d.m, b.v) apresentaram números semelhantes para ambos os fenômenos, sendo 89 ocorrências de PSE e 91 de EPE. O teste apontou diferença significativa $\left(\mathrm{X}^{2}(1)=77,2 ; \mathrm{p}<0,01\right)$, fato que indica o favorecimento do PSE pelos tipos silábicos desvozeados. O resultado reforça os achados de Nascimento (2016), a qual constatou que o contexto desvozeado favoreceu a emergência de PSE. De maneira semelhante, Silveira e Seara (2009) e Cristófaro-Silva e Almeida (2008) relataram que o vozeamento favorece a emergência de EPE.

Novamente, considera-se o resultado categórico do tipo silábico b.v em relação à emergência de PSE. Embora composto por duas consoantes vozeadas, a palavra óbvio provou-se resistente à inserção de vogal epentética. Como relatado nas pesquisas aqui mencionadas, embora tipos silábicos vozeados atuem como um atrator para a emergência de EPE, esta palavra apresenta um percurso distinto, caracterizado pela maior emergência de PSE.

Também foi realizado um $\mathrm{X}^{2}$ comparando a emergência de PSE entre os tipos silábicos desvozeados (k.t, f.t, p.t), o qual relatou apenas diferenças não significativas $\left(\mathrm{x}^{2}(2)=0,44 ; p=0,80\right)$, mostrando que os três tipos favoreceram semelhantemente os PSE. Por fim, também foi comparado o comportamento dos tipos silábicos vozeados (d.v, d.m) entre si, desconsiderando o tipo b.v. O resultado do teste mostrou que ambos os tipos silábicos apresentaram ocorrências de PSE e EPE semelhantes $\left(\mathrm{x}^{2}(1)=0,05 ; p=0,83\right)$. Desse modo, nota-se que $\mathbf{d . v}$ e $\mathbf{d} \cdot \mathbf{m}$ favoreceram igualmente a emergência de EPE e resistiram à emergência de PSE. 
A Figura 7 apresenta dados da análise da variável vozeamento sobre a duração relativa de EPE em gráficos de Boxplots e intervalo de confiança.

Figura 7 - Duração relativa da vogal epentética por vozeamento
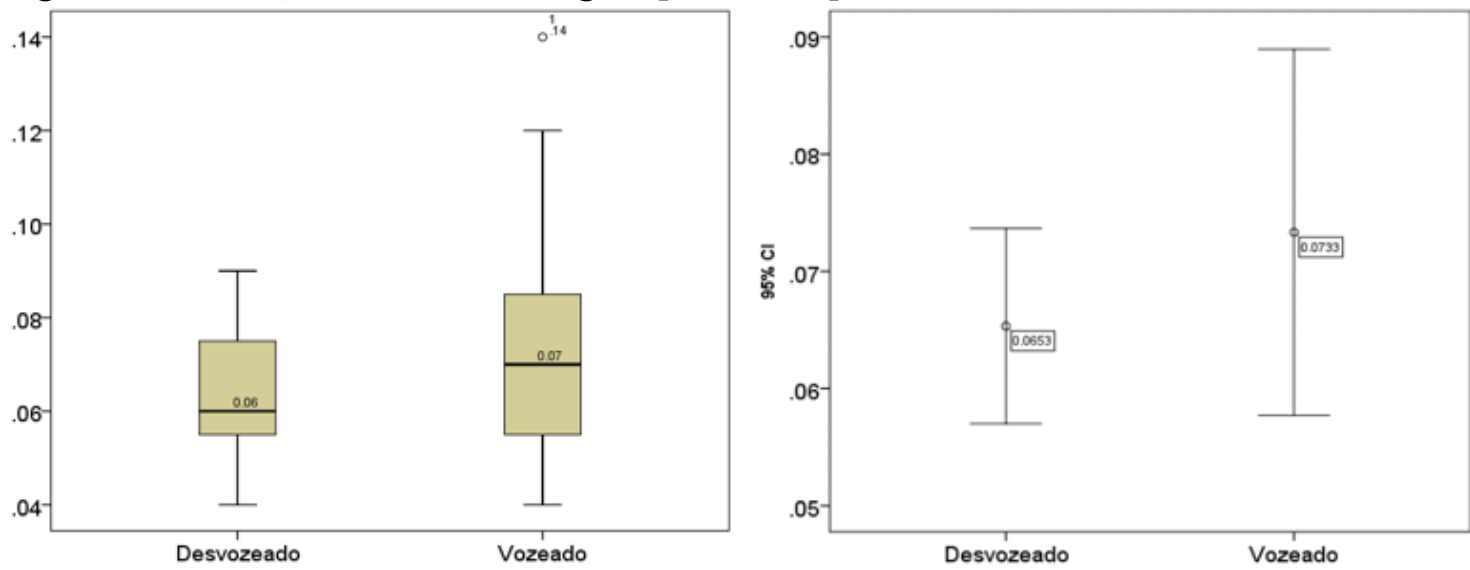

Fonte: Elaboração própria.

Embora o contexto vozeado tenha apresentado um número de ocorrências maior de EPE do que o contexto desvozeado, o teste de Wilcoxon $(Z(1)=-0.49 ; p=0,6)$ mostrou que houve apenas diferença não significativa na duração relativa da EPE por vozeamento. Assim, os dados desta pesquisa diferem de Cristófaro-Silva e Almeida (2008) e Nascimento (2016), que relataram maior duração de EPE no contexto vozeado.

Conclui-se a variável vozeamento notando que tipos silábicos desvozeados favorecem a emergência de PSE enquanto os vozeados apresentam uma competição entre os dois fenômenos. O fato segue princípios dos Modelos Multirrepresentacionais e demonstra que ambas as realizações (com PSE e com EPE) competem de modo probabilístico para a emergência no contexto vozeado. Notou-se também o comportamento distinto do tipo silábico b.v. Por fim, percebeu-se que, independente do contexto de vozeamento, a duração da EPE é semelhante.

A seguir é apresentada a análise comparativa das durações relativas da vogal epentética e plena. Nesta variável, são comparadas as durações das vogais plenas e EPE analisadas neste estudo, apresentadas na Figura 8. 
V. 10 (1)

121-140

jan./abr.

2020
Figura 8 - Duração relativa das vogais epentética e plena
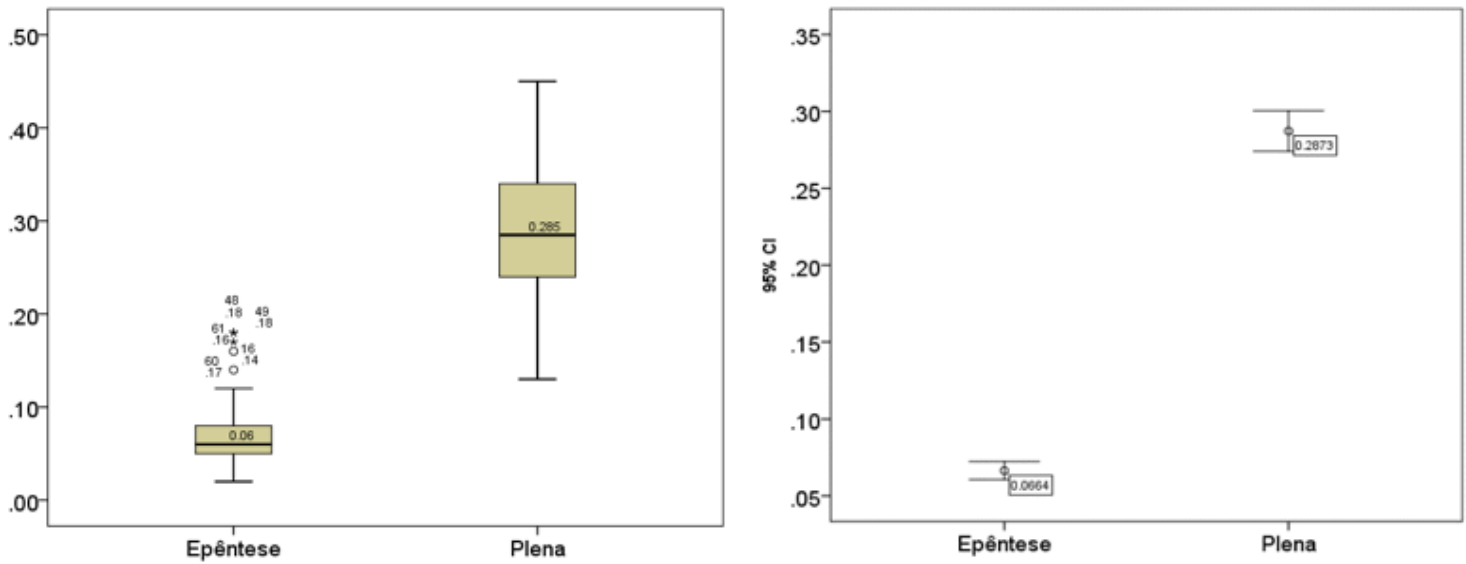

Fonte: Elaboração própria.

O teste estatístico utilizado foi o Wilcoxon $(Z(1)=-8,94$; $p<0,01)$, o qual constatou que há diferença significativa entre as durações das vogais plenas e epentéticas. As durações relativas médias obtidas nesta pesquisa foram de 0,29 para a vogal plena de um total de 120 ocorrências, enquanto a vogal epentética obteve 0,06 para 106 ocorrências.

Os resultados mostram que a duração da vogal plena é significativamente maior que a EPE. A maior duração relativa da vogal epentética foi de 0,18 na palavra advogado. Entretanto, a maior duração da vogal epentética ainda é menor que a maioria das vogais plenas obtidas. Apenas oito vogais plenas apresentaram duração igual ou inferior às vogais epentéticas.

A literatura indica que a vogal plena tende a uma maior duração do que a epentética. Cristófaro-Silva e Almeida (2008) relataram médias de $30 \mathrm{~ms}$ para vogais epentéticas e $49 \mathrm{~ms}$ para plenas. Silveira (2007) descreveu 13,7 ms para EPE e 106 ms para a vogal plena, além de Nascimento (2016) que também relatou menor duração da vogal epentética, apesar de não significativa. Já a pesquisa de Cantoni (2015) relatou que, além da vogal plena ter maior duração do que vogal epentética, há uma distinção entre vogais epentéticas tônicas (aquelas que mudam o acento silábico da palavra) e átonas. Tomando como indício a pequena duração da vogal epentética, é possível inferir que um PSE emerge a partir da redução da vogal epentética, como hipotetizado por Nascimento (2016). De maneira gradiente, o falante reduz a duração da vogal epentética culminando em um PSE.

A análise desta variável indica que o falante realiza a vogal plena com duração significativamente maior do que a vogal epentética. 
Há maior variação entre as vogais plenas quando comparadas às vogais epentéticas, que são reduzidas de forma gradiente propiciando a emergência de um PSE. Passamos no próximo parágrafo à análise da variável indivíduo.

A Figura 9 apresenta o número de ocorrências de PSE por indivíduo. O experimento elaborado contou com seis palavras propícias à emergência de PSE, lidas três vezes por 20 informantes, totalizando 18 palavras.

Figura 9 - Realização de PSE por indivíduo

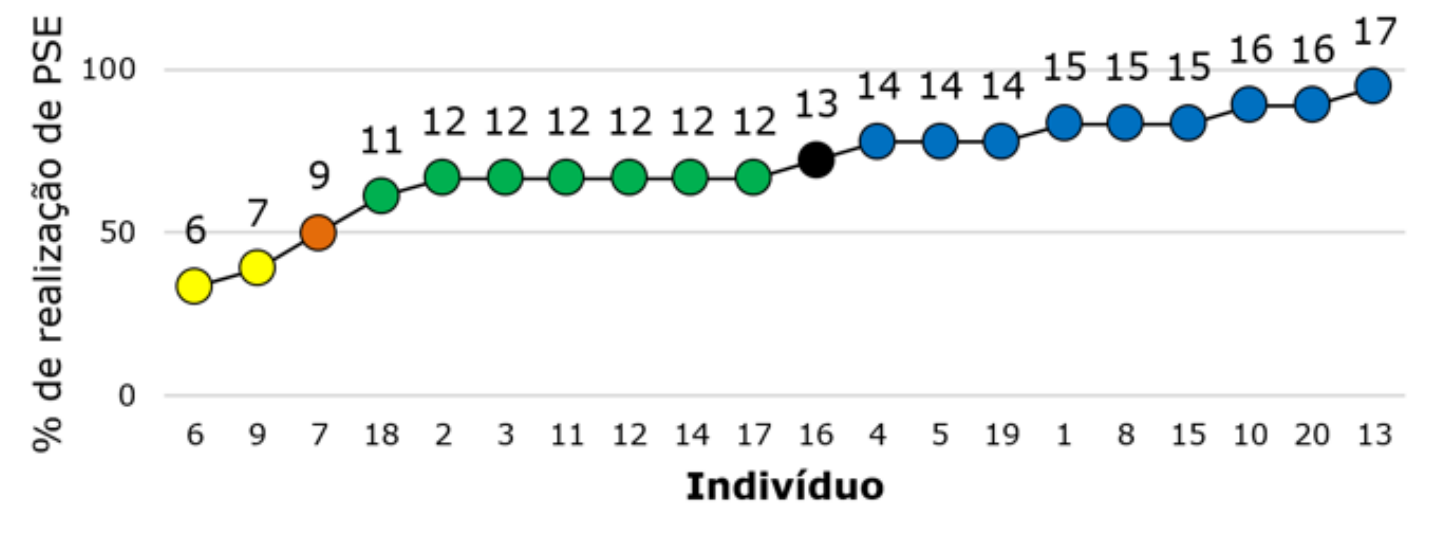

Fonte: Elaboração própria.

Ao observar a Figura 9, percebe-se que a maioria dos informantes produziu PSE em mais de 50\% das ocorrências. A média de PSE por indivíduo foi de 13 ocorrências (71\%), indicada pelo marcador preto.

O marcador laranja representa o informante 7, além de apontar a mediana do experimento total. Esse informante apresenta marcante competição entre a realização com PSE e a vogal epentética, pois realizou 50\% de ocorrências associadas a cada um dos fenômenos.

Apenas os informantes 6 e 9 (marcadores amarelos) realizaram menos PSE do que EPE. Nas realizações do informante 6, observamos a emergência de EPE nas três ocorrências da palavra apto, em duas ocorrências de pacto e uma de afta. Todavia, os tipos silábicos desvozeados desfavoreceram a emergência de PSE. Assim, o comportamento deste informante apresentou-se influenciado por um atrator estranho à maioria dos seus pares, cujo comportamento distingue-se em relação aos referidos itens lexicais.

Os informantes do grupo verde $(18,2,3,11,12,14$ e 17) favoreceram a emergência de PSE, porém ainda abaixo da média do grupo 
V. 10 (1) 121-140 jan./abr 2020
(13). O informante 18 realizou 11 ocorrências de PSE enquanto os outros produziram 12 PSE, cada. Entretanto, nota-se que esses informantes favorecem o PSE, pois estão acima da mediana do experimento, desfavorecendo a EPE. Notou-se que os informantes 2, 3, 11, 12, 14 e 17 produziram um PSE em todas as palavras compostas por tipos silábicos desvozeados e em óbvio (contextos favoráveis a um PSE, como relatado nas variáveis anteriores). As únicas palavras que os informantes não produziram um PSE foram advogado e administrar, desfavoráveis devido ao vozeamento.

Por fim, os informantes representados pelos marcadores azuis produziram PSE em números acima da média do grupo. O informante 13 realizou o maior índice de PSE, sendo que das 18 realizações propícias ao PSE, apenas uma ocorrência da palavra advogado contou com a EPE vocálica. De maneira similar, outros informantes do grupo também optaram por um PSE em vez de reestruturarem a sílaba através da EPE. Conclui-se que os referidos informantes encontram-se num estágio avançado de desenvolvimento de PSE.

Com base nos dados apresentados na Figura 9, notam-se indivíduos em estágios distintos de realização de PSE. Embora a maioria dos informantes produzam PSE heterossilábicos, nenhum favoreceu categoricamente o fenômeno. Também foram observados indivíduos resistentes aos PSE, reforçando a variação no nível individual. Tal averiguação no nível individual coaduna com o modelo de análise dos SACs e dos Modelos Multirrepresentacionais, sendo de difícil explicação pelos modelos fonológicos tradicionais. A partir desta visão, a linguagem, por ser um sistema aberto, sofre influências tanto internas quanto externas. Por este motivo, os PSE são influenciados pelas variáveis analisadas, bem como pelo uso/experiência individual da linguagem por cada informante. Passamos à análise da duração relativa das vogais plenas e epentéticas a seguir.

Como relatado anteriormente, notou-se uma diferença marcante entre a duração relativa das vogais plenas e epentéticas. Vogais plenas foram consideravelmente mais longas do que vogais epentéticas, com exceção de um caso. A fim de averiguar se as vogais produzidas por cada informante apresentam diferenças de duração relativa, a Figura 10 apresenta as durações relativas médias das vogais plenas (vermelho) e epentéticas (azul) de cada indivíduo organizadas em ordem crescente. Os marcadores correspondem aos indivíduos deste estudo, com seus números indicados. 
Testes estatísticos individuais (teste $t$ pareado e Wilcoxon quando não paramétrico) foram realizados para averiguar as diferenças na duração das vogais epentética e plena por indivíduo, a depender do tipo de teste mais recomendado para o conjunto de dados (DANCEY; REIDY, 2006). Informantes representados por ( $\boldsymbol{\Delta}$ ) apresentaram diferenças significativas na duração relativa das vogais, enquanto informantes representados por $(\bullet)$ apresentaram diferença não significativa. Foi impossível realizar teste estatístico com os dados do informante 13, indicado na figura pelo quadrado ( $\mathbf{\bullet})$, pois apenas uma ocorrência de EPE foi constatada.

Figura 10 - Duração das vogais plena e epentética de cada indivíduo

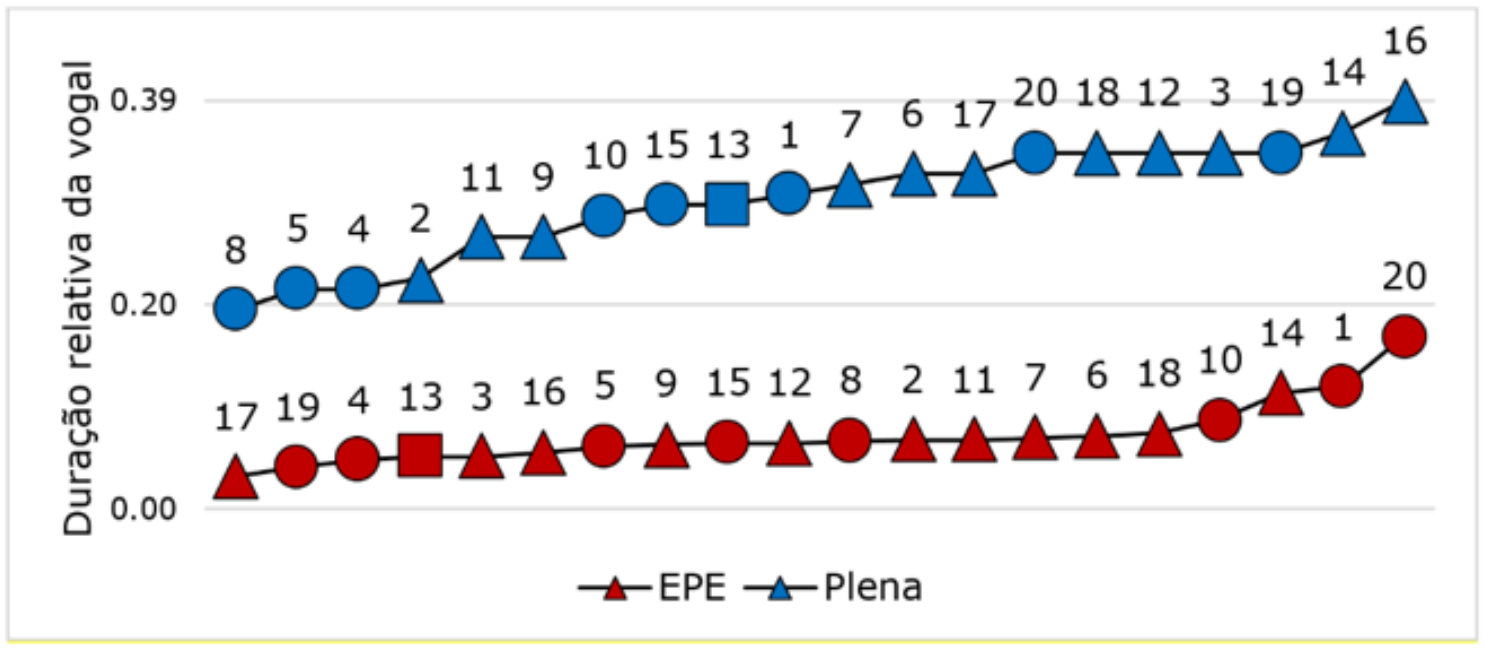

Fonte: Elaboração própria.

A diferença na duração de ambas as vogais dos indivíduos $2,3,6,7,9,11,12,14,16,17$ e 18 foram significativas. Por sua vez, os informantes $1,4,5,8,10,15,19$ e 20 produziram vogais plenas consideravelmente mais longas que a $\mathrm{EPE}$, porém os testes estatísticos apontaram diferenças não significativas. Entretanto, considerando a alta duração da vogal plena, acredita-se que tais resultados sejam decorrentes ao pequeno número de dados analisados por informante, pois poucas ocorrências de EPE foram utilizadas para a realização dos testes, o que acarreta maior probabilidade de erro tipo II (DANCEY; REIDY, 2006).

Por fim, constata-se que os informantes realizam distinção na duração das vogais, pois todos produziram vogais plenas com durações relativas médias maiores do que as epentéticas, sendo que a maioria apresentou diferenças estatisticamente significativas. Tal distinção entre ambas as vogais através da duração, também constatada 
V. 10 (1) 121-140 jan./abr 2020 por Cristófaro-Silva e Almeida (2008), reforça a gradiência na duração da vogal epentética também no nível individual, a qual mostrase consideravelmente baixa, diferente da vogal plena com durações relativas altas. Encerrando a seção de análise e discussão dos dados do estudo, são apresentadas a seguir as considerações finais.

\section{Considerações finais}

O objetivo desta pesquisa foi analisar os Padrões Silábicos Emergentes (PSE) em contexto heterossilábico no Português Brasileiro (PB). A pergunta problema que norteou este estudo foi: Quais os fatores associados à emergência de PSE heterossilábicos no PB? A hipótese defendia que os PSE no PB emergem pela redução gradiente da vogal epentética, influenciada por variáveis como tipo silábico, vozeamento e indivíduo.

A partir dos resultados encontrados neste estudo, a hipótese levantada foi confirmada, pois percebeu-se que tipos silábicos atuam como atratores para a emergência de PSE e contextos desvozeados favorecem significativamente a emergência do fenômeno. Além disso, variação interindividual marcante também foi observada.

Os principais resultados desta pesquisa foram: (a) os tipos silábicos f.t, p.t, k.t e b.v mostraram-se atratores para a emergência de PSE no PB, enquanto d.v e d.m apresentaram competição entre o fenômeno e a ocorrência de EPE; (b) contextos desvozeados favoreceram a emergência de PSE no PB, enquanto os vozeados apresentaram competição com a EPE. Entretanto, destaca-se o comportamento do tipo silábico vozeado b.v, que favoreceu o PSE; (c) a vogal plena apresentou durações significativamente maiores do que a epentética. Maior variação foi observada na duração da vogal plena. As vogais epentéticas apresentaram durações médias relativamente pequenas, as quais tendem a ser reduzidas e culminam em um PSE; (d) a maioria dos indivíduos analisados favoreceu a emergência de PSE, sendo que apenas dois favoreceram a ocorrência de EPE. Sobre a duração das vogais plena e epentética, os indivíduos mostraram ter noção da distinção entre ambas através da duração relativa das vogais.

Conclui-se que a emergência de PSE no PB é um fenômeno gradiente, o qual ocorre predominantemente em contextos desvozeados. Adicionalmente, observa-se marcante competição entre a emergência de PSE e EPE nos tipos silábicos vozeados, a qual pode, futuramente, 
favorecer os PSE neste contexto devido ao atrator pelo PSE já existente nos tipos desvozeados. Tal fenômeno foi constatado em diferentes estágios no nível individual, sendo favorecido em relação à epêntese, porém sem nenhum índice categórico. Por fim, os PSE heterossilábicos no PB mostram-se decorrentes de outro fenômeno gradiente, a redução da vogal epentética, culminando em sua elisão.

Em trabalhos futuros envolvendo a emergência de PSE no PB, esperamos analisar se o fenômeno ocorre em outras posições silábicas, além de emergir através da redução da vogal plena. Também espera-se analisar a influência de palavras para a emergência de PSE devido ao papel do item lexical como lócus da representação mental, buscando averiguar, por exemplo, se a palavra óbvio é uma exceção para o tipo silábico b.v que favoreceu o PSE mesmo sendo vozeado. Também é relevante uma pesquisa sobre a duração de vogais epentéticas átonas e tônicas. Por fim, considerando a linguagem um sistema aberto e complexo que pode sofrer influências de outros sistemas, buscaremos analisar os efeitos dos PSE no PB para a aquisição dos padrões alvos de línguas adicionais.

\section{Referências}

BARBOZA, Clerton Luiz Felix. Efeitos da palatalização das oclusivas alveolares do português brasileiro no percurso de construção da fonologia do inglês língua estrangeira. 263 f. Tese (Doutorado em Linguística) - UFC, Fortaleza, 2013.

BECKNER et al. Language is a complex adaptive system: position paper. Language Learning, Michigan, v. 51, n. 1, p.1-26, 2009.

BOERSMA, Paul, WEENIK, David. Praat: doing phonetics by computer. Version 6.1.03. 2019. Disponível em <http://www.praat.org. >. Acesso em: 13 set. 2019.

BYBEE, Joan. Phonology and language use. Cambridge: Cambridge University Press, 2001.

CANTONI, Maria M. A epêntese no português brasileiro em uma perspectiva multirrepresentacional. Gragoatá, Niterói, v. 20, p. 231-246, 2015.

CRISTÓFARO-SILVA, Thaïs; ALMEIDA, Leonardo. On the nature of epenthetic vowels. In: BISOL, Leda; BRESCANCINI, Claudia. (Org.). Contemporary Phonology in Brazil. 1. ed. Cambridge: Cambridge University Press - Cambridge Scholars Publishing Series, 2008. p. 193-212.

CRISTÓFARO-SILVA, Thaïs; BARBOZA, Clerton; GUIMARÃES, Daniela; NASCIMENTO, Katiene. Revisitando a palatalização no português brasileiro. Revista de Estudos da Linguagem, Belo Horizonte, v. 20, n. 2, p. 59-89, dez. 2012. 
V. 10 (1) $121-140$ jan./abr. 2020

DANCEY, Christine P.; REIDY, John. Estatística sem matemática para psicologia: usando SPSS para Windows. Porto Alegre: Artmed, 2006.

IBM CORPORATION. IBM SPSS statistics. Version 20.0. 2011.

LARSEN-FREEMAN, Diane; CAMERON, Lynne. Complex systems and applied linguistics. Oxford: Oxford University Press, 2008.

NASCIMENTO, Katiene. Emergência de Padrões Silábicos no Português Brasileiro e seus reflexos no Inglês Língua Estrangeira. $187 \mathrm{f}$. Tese (Doutorado em Linguística) - UECE, Fortaleza, 2016.

PEIXOTO, C. S. . Características acústicas do processo de epêntese do glide [j] diante de [s] não-palatalizado. Revista do GEL, Araraquara, v. 08, p. 156-171, 2011.

PIERREHUMBERT, Janet B. Exemplar dynamics: word frequency, lenition and contrast. In: BYBEE, Joan; HOPPER, Paul (Comp.). Frequency effects and the emergence of linguistic structure. Amsterdam: John Benjamins, 2001. p. 137158.

SILVEIRA, Francine; SEARA, Izabel C.. A Vogal epentética em encontros consonantais heterossilábicos no português brasileiro: um estudo experimental. Revista do GEL, São Paulo, v.6, n.2, p.9-35, 2009. 